\title{
Diaphragmatic stimulation caused by cardiac resynchronization treatment
}

\author{
Rahman Shah MD, Zoe Qualls NP MSN
}

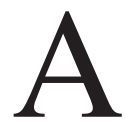

69-year-old man with a history of severe nonischemic cardiomyopathy managed with a cardiac resynchronization-defibrillator presented to the outpatient clinic with uncomfortable pulsation over the left upper-abdominal area when lying on his left side. He was hemodynamically stable. When he was recumbent in a left-lateral position, there were visible and palpable contractions of the left upper-abdominal wall musculature (Figure 1; Appendix 1, available at www.cmaj.ca/ lookup/suppl/doi:10.1503/cmaj.150986/-/DC1).

We suspected diaphragmatic contraction caused by inadvertent phrenic nerve stimulation by the left ventricular lead. We confirmed the diagnosis noninvasively by reducing the left ventricular pacing amplitude of the lead. ${ }^{1}$

Phrenic nerve stimulation has been described in up to one-third of patients with traditional cardiac resynchronization-defibrillator devices because of the proximity of the phrenic nerve to the pericardial veins, which makes the nerve susceptible to stimulation by the high-amplitude left ventricular lead. ${ }^{2}$ This problem has become much less common with the recent development of quadripolar lead technology. ${ }^{3}$

Phrenic nerve stimulation can be continuous or paroxysmal and can cause dyspnea, uncomfortable muscle twitching, hiccups and general malaise. ${ }^{2}$ It can be challenging to diagnose for those not familiar with cardiac resynchronization-defibrillator technology. ${ }^{4}$

Phrenic nerve stimulation is highly posturedependent. It occurs more often when the patient is in a left-lateral position rather than in a supine position. ${ }^{2}$ Although phrenic nerve stimulation is not life-threatening, it can cause substantial discomfort to the patient. ${ }^{2}$ The problem can almost always be mitigated noninvasively with electrical reprogramming of the cardiac resynchronization-defibrillator. ${ }^{5}$

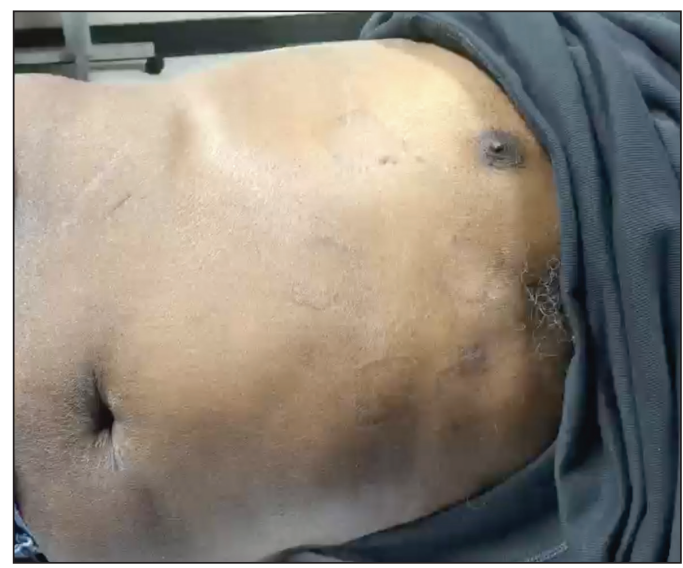

Figure 1: A 69-year-old man, with a history of severe nonischemic cardiomyopathy managed with a cardiac synchronization-defibrillator, lying in a left-lateral position with contractions of the left upper-abdominal wall musculature.

\section{References}

1. Daubert JC, Saxon L, Adamson PB, et al. EHRA/HRS expert consensus statement on cardiac resynchronization therapy in heart failure: implant and follow-up recommendations and management. Heart Rhythm 2012;9:1524-76.

2. Moubarak G, Bouzeman A, Ollitrault J, et al. Phrenic nerve stimulation in cardiac resynchronization therapy. J Interv Card Electrophysiol 2014;41:15-21

3. Stiles S. Fewer CRT-lead-related complications with quadripolar vs bipolar leads: MORE-CRT Trial. Medscape 2014 Sept 12. Available: www.medscape.com/viewarticle/831630 (accessed 2015 Dec. 18).

4. Akrawi H, Hulbert D. Unusual cause of a pulsatile abdominal mass. Emerg Med J 2007;24:602.

5. Biffi M, Exner DV, Crossley GH, et al. Occurrence of phrenic nerve stimulation in cardiac resynchronization therapy patients: the role of left ventricular lead type and placement site. Europace 2013;15:77-82.
Competing interests: None declared.

This article has been peer reviewed.

The authors have obtained patient consent.

Affiliations: Division of Cardiovascular Diseases (Shah, Qualls), Department of Medicine, University of Tennessee; Memphis VA

Medical Center (Qualls),

Memphis, Tenn.

Correspondence to:

Rahman Shah,

Shahcardiology@yahoo.com

CMAJ 2016. DOI:10.1503

/cmaj.150986
Please see the following video online: A patient with phrenic nerve stimulation caused by a cardiac resynchronization-defibrillator. www.cmaj. ca/lookup/suppl/doi:10.1503/cmaj.150986/-/DC1 